University of Nebraska - Lincoln

DigitalCommons@University of Nebraska - Lincoln

3-8-1985

\title{
Seasonal Temperature Forecasts as Products of Antecedent Linear and Spatial Temperature Arrays
}

Merlin Lawson

Randall S. Cerveny

Follow this and additional works at: https://digitalcommons.unl.edu/geosciencefacpub

Part of the Earth Sciences Commons

This Article is brought to you for free and open access by the Earth and Atmospheric Sciences, Department of at DigitalCommons@University of Nebraska - Lincoln. It has been accepted for inclusion in Papers in the Earth and Atmospheric Sciences by an authorized administrator of DigitalCommons@University of Nebraska - Lincoln. 


\title{
Seasonal Temperature Forecasts as Products of Antecedent Linear and Spatial Temperature Arrays
}

\author{
Merlin P. Lawson and Randall S. CeRveny \\ Climatology Program, Department of Geography, University of Nebraska-Lincoln, Lincoln NE 68588
}

(Manuscript received 10 August 1984, in final form 8 March 1985)

\begin{abstract}
Our objective is to evaluate the potential for extracting the maximum information contained in antecedent temperature patterns that operationally could be used in formulating winter seasonal forecasts in the United States. In particular, examination of the predictability of winter temperatures given autumn temperatures is made using derived contingency tables, discriminant equations of antecedent principal components, and canonical correlation analysis.

Contingency tables were constructed based on tercile classifications of a seventy-five year dependent record (1895-1969). Testing of an independent data period (1970-78) using these tables produced winter forecasts with no appreciable skill in the aggregate $(-0.04)$. Discriminant analysis derived linear combinations of the five principal components of the antecedent seasonal (autumn) temperatures to distinguish between specific terciles of the predictand season (winter). Despite encouraging results for the dependent period, forecast skill for the independent test period achieved no significant score $(-0.04)$.

Unfortunately, both of these forms of analysis suffer imposed spatial limitations which restrict the scope of our investigation. Canonical correlation analysis is capable of relating the total spatial variance of fall temperatures to that of the winter temperatures for the entire United States. In this study, the technique was used to isolate seasonal patterns in winter temperature data that are correlated in time with fall temperature patterns for the same region. Summation of the first 20 canonical variate pairs suggests that autumn and winter temperatures over the continental United States are not closely related to one another.
\end{abstract}

\section{Introduction}

Severe short-term fluctuations in seasonal weather characteristics have resulted in tremendous socioeconomic disruptions, especially in the supply of food and demand on water and energy resources (Shelton, 1978; Changnon, 1979). The benefits of accurate long-range forecasts are estimated to be in the billions of dollars for the United States economy alone (Quayle and Diaz, 1980; Warren and LeDuc, 1981; McCullough, 1983). For example, Phillips et al. (1978) concluded that seasonal forecasts with an accuracy of only $75 \%$ would result in an increase of $\$ 1.4$ billion annually in expected net farm income $(5.6 \%$ of the total). These savings would be derived because of improved managerial decisions assisted by the availability of long-range forecasts. There is overwhelming evidence to suggest that the public places an exceptionally high priority on research potentially beneficial to developing greater skill in extended weather forecasts (Nicholls, 1980; Riebsame, 1983).

Recent evaluations of seasonal (temperature and precipitation) forecasts have proven discouraging (Bettge et al., 1981; Nicholls, 1980; Preisendorfer and Mobley, 1984), especially when compared to the optimism expressed by Namias (1968) almost two decades ago. Based on anticipated and realized im- provements in data sources (including satellite measurements), electronic computing, and better understanding of atmospheric behavior, Namias speculated that within five to ten years "economically valuable forecasts" would be able to provide: 1) monthly means and other weather statistics with double the skill then possible, 2) prediction of seasonal general weather characteristics, 3 ) estimates of the character of a season one year ahead, and 4) estimates of average climatic deviations from normal for a fiveor possible ten-year period $(1968$, p. 466$)$. While the current state of long-range prediction falls short of these expectations, the policy statement adopted by the Council of American Meteorological Society in September 1983 recognizes signs of "improvement in predicting monthly or seasonal averages." The statement concludes that "even small improvements should be of substantial economic benefit" (AMS, 1983, p. 1387).

The unsatisfactory state of long-range forecasts is understandable when one recognizes the challenge presented in attempting to model an unbounded atmospheric system having complex interactions on a global scale. As our ability to obtain more data of a better quality improves, coupled with increased computer capacity, it is probable that our formulation of physical quasi-stable states will similarly evolve. 
There is much recent work in the area of atmospheric forcing by sea surface temperature anomalies, particularly in the equatorial Pacific (e.g., Barnett, 1981a). Knowledge gained through this work is being developed and applied to modeling experiments, with modest success (e.g., Chervin et al., 1980). Until full understanding is achieved, in order to successfully forecast beyond a few weeks, we will have to rely more on the estimation of synoptic tendencies with the use of statistical aggregates. The forecasting techniques developed primarily for generating these estimates have traditionally involved the use of analogs, trends, teleconnections, regression analyses, climatological contingencies, air-sea interactions, and occasionally, cosmic influences generally associated with solar or lunar periodic behavior (Namias, 1978a; Pielke, 1977; Nicholls, 1980). Recognizing the current lack of dynamic physical explanations for anticipating most extended weather states, it is necessary for us to continue to seek improvements in our use of empirical statistics. The focus of this paper is directed toward this goal.

Our objective is to evaluate the potential for extracting the maximum information contained in antecedent temperature patterns that operationally could be used in formulating a predictive model for seasonal forecasts. Two of the most commonly employed techniques for deriving a statistical association between consecutive seasons are the use of contingency tables and regression equations. Namias $(1964,1978 \mathrm{a})$ has demonstrated with the use of contingency functions that thermal anomalies in selected regions have a tendency to persist between two seasons. Van Loon and Jenne (1975) have suggested regression functions are preferable to contingency analysis. In their view, contingency analysis lacks an ability to account for any potential trend existing in the time series. They contend regression equations provide a continuum of expected means in terms of probability estimates.

These and similar studies typically lack a comparative analysis of the respective skill contributed by these techniques for an independent forecast period. In this study, this verification of skill and subsequent evaluation of these techniques will be achieved by employing the following procedure:

1) Create contingency tables using individual stateweighted winter seasonal temperatures (Diaz and Quayle, 1978) over the conterminous United States for a 75-year dependent period.

2) Prepare seasonal forecasts (hindcasts) exclusively utilizing these contingencies for an eight-year independent period.

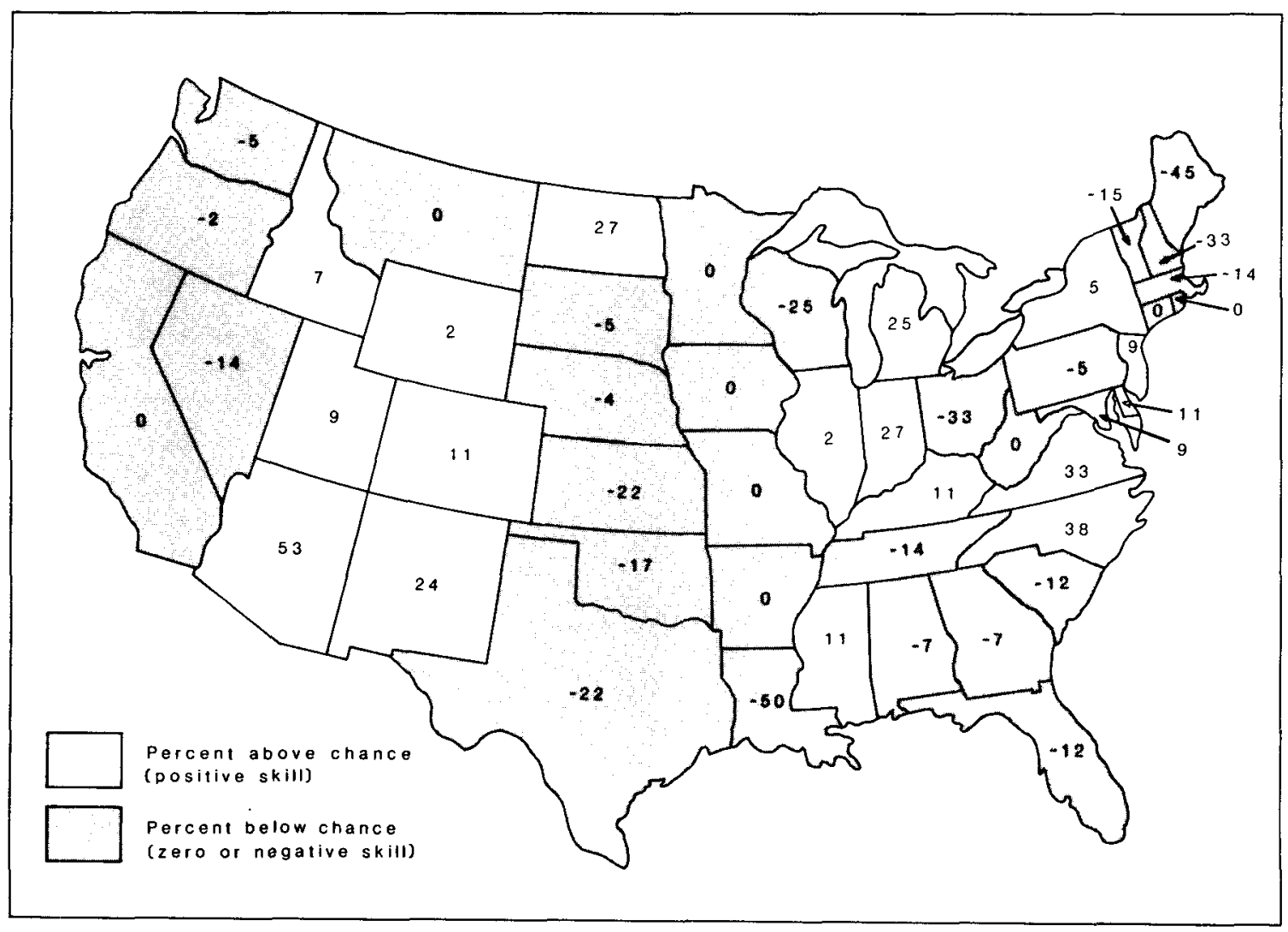

FIG. 1. Contingency analysis summary skill: independent forecast period, autumn to winter 1970-78. 
3) Derive discriminant functions capable of classifying winter temperature for the same dependent period.

4) Prepare seasonal forecasts (hindcasts) utilizing only these discriminant functions for an identical independent period.

5) Compute and compare the respective skill scores associated with these techniques and assess the potential for incorporating these methods into operational extended forecast models.

\section{Research procedure \\ a. Contingency analysis}

The climatology of persistence (or reversal) of seasonal temperature and precipitation anomalies for the conterminous United States has been developed and reported in considerable detail in a previous study (Lawson et al., 1984). Because it is generally recognized that temperature characteristics are more spatially and temporally cohesive than precipitation characteristics, we restricted this investigation to a consideration of antecedent fall temperatures as they relate to winter temperatures. The winter season generally is regarded as being most predictable, but not by a large margin (Preisendorfer and Mobley, 1984). Statistical prediction of North America air temperatures using sea surface temperature anomalies, for example, achieved higher skill in winter than in summer (Barnett, 1981b).

Contingency tables representing the fall-winter associations were derived using 75 years of stateweighted data from 1895-1969/70 (Diaz and Quayle, 1978). Temperature averages were calculated for the fall (SON) and winter (DJF) seasons for each year in the study period. These seasonal values were ranked and classified into three equally probable classes, termed terciles, of cold, moderate, and warm temperatures for the 75-year period up to the winter of $1969 / 70$.

A $3 \times 3$ contingency analysis reveals the association of winter temperature values with the antecedent fall characteristics. Assuming equal probabilities, no matter what is observed during the fall, the winter season has a $33 \%$ probability of being either cold, moderate, or warm. The observed deviation (that is excess or deficit departure) from chance can then be calculated for the winter season. Regional analysis of these deviations suggests: 1) a slight reversal of temperature in the prairie states with strong persistence in the northwest and southeast for a cold autumn, 2) a

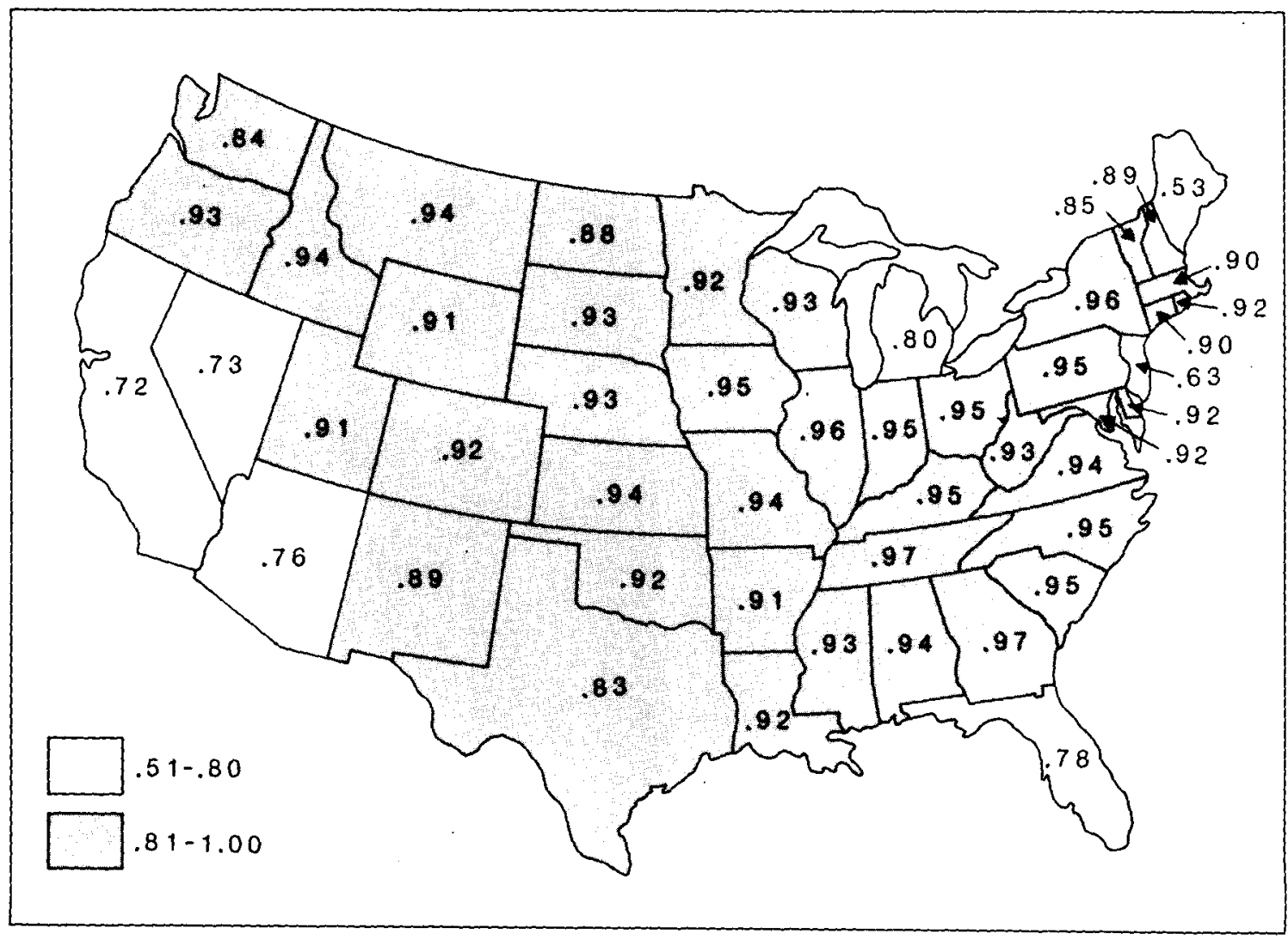

FIG. 2. Cumulative communalities of autumn temperatures. 
tendency for a warm winter in the northeast and a cool winter in the mountain states for a moderate autumn, and 3) strongest persistence west of the Mississippi for a warm fall (Lawson et al., 1984).

The percentage of excess over chance contained in these contingency relationships represents the potential degree of forecasting skill using these relationships. A value of $9.4 \%$ over the United States for the autumn to winter season would suggest that contingency forecasts should attain a success that exceeds that of chance, perhaps approaching skill normally achieved by seasonal forecasts (Namias, 1978a). In contrast to the success of contingency relationships, our analysis of straight persistence accounts for only $4.8 \%$ above chance for the conterminous states.

\section{b. Contingency forecasts}

The contingency tables previously derived for the dependent data period of 1895-1969 were used to produce seasonal forecasts (hindcasts) for the independent data period of 1970-78. Seasonal forecasts for each state were produced by using the observed tercile of the antecedent season and comparing this tercile to the climatological contingency table developed for each state. Whenever no dominant seasonal contingency existed for a particular antecedent season, no forecast could be made. A total of 321 forecasts (83.6\%) were able to be made out of a possible 384 ( 48 states $\times 8$ years). The accuracy of each contingency forecast was evaluated objectively by calculating the skill score, where

Skill score

$$
=\frac{\begin{array}{c}
\text { Total correct forecasts } \\
- \text { number expected by chance }
\end{array}}{\text { Total state forecasts }},
$$

A skill score of zero represents no skill; a positive value implies skill above chance; and a negative value denotes skill at a level less than that expected by chance.

Given the encouraging results of the dependent period, it is surprising to note the lack of predictive ability during the independent time period. The summary skill score for the 48 states $(-0.04)$ reveals no

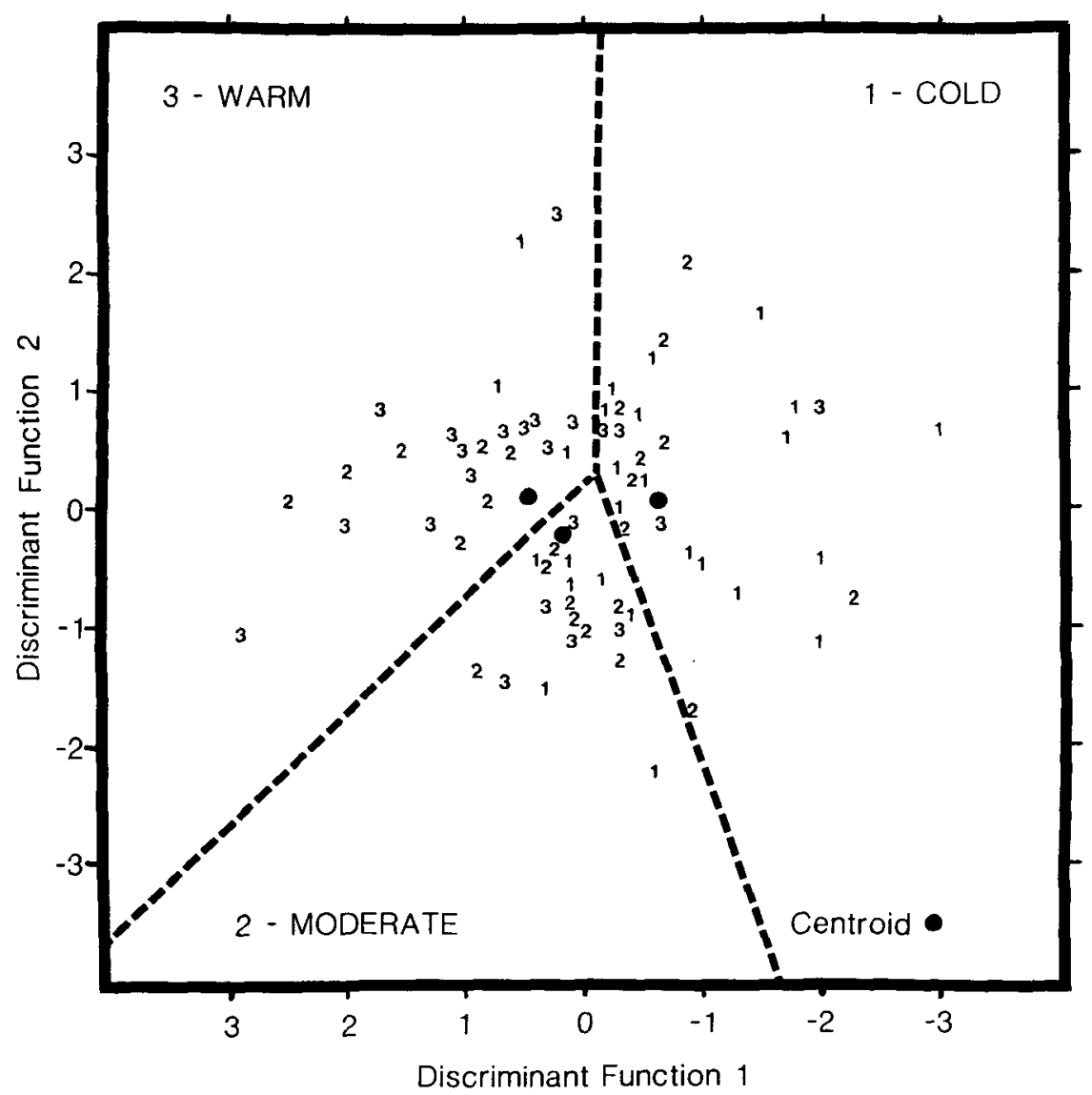

FIG. 3. The discriminant analysis requiring two functions to isolate three classes of winter temperatures of Idaho. 
appreciable predictive ability. Contingency analysis for the independent forecast period seems to be most successful in the mountain states, with varied skill dispersed throughout the eastern United States (Fig. 1). Arizona forecasts had the greatest skill (0.53), which may be due in part to the large positive temperature trend at Phoenix over the last decade. Because the contingency method is influenced by persistence, the high skill associated with Arizona may be more a function of the persistence of the temperature anomaly for that state. Louisiana is distinguished by an equal, but negative, forecast skill $(-0.50)$. Although the results from the dependent period were promising, the predictive power of contingency analysis was negligible for the eight-year independent period. It should be recognized that the aggregate skill for all states over the eight-year period $(-0.04)$ is statistically more stable than the summary skill for each individual state because of the respective " $n$ " size involved.

\section{c. Discriminant analysis}

More complete examination of forecasting methodologies which utilize antecedent weather patterns can be achieved by employing various regression techniques (van Loon and Jenne, 1975). One difficulty associated with the use of regression techniques involving more than one variable is the imposed necessity to adjust for high intercorrelations among variables. Certain variables that may contribute substantially to the predictand of the regression equation could be excluded (as in a step-wise approach), or could lead to compromising the statistical significance of a multiple-regression model (Barnett and Hasselmann, 1979). To overcome problems inherent to regression techniques, our methodology includes a combination of discriminant and principal component analyses. Discriminant analysis distinguishes between specific classes of the predictand through the use of linear combinations of the predictor set in a fashion similar to regression techniques. Principal component analysis is used to avoid the liabilities of multicollinearity.

Principal component analysis in this study produced orthogonal functions (eigenvectors) based on a 48 $\times 48$ correlation matrix. This matrix contained the temporal associations of state-averaged fall temperatures over the time period of 1895-1969. In contrast to the $O$-mode analysis (Balling, 1984) on this type of dataset that has been accomplished in the past (Diaz and Fulbright, 1981; Gilman, 1957), we are not interested in obtaining the most common spatial

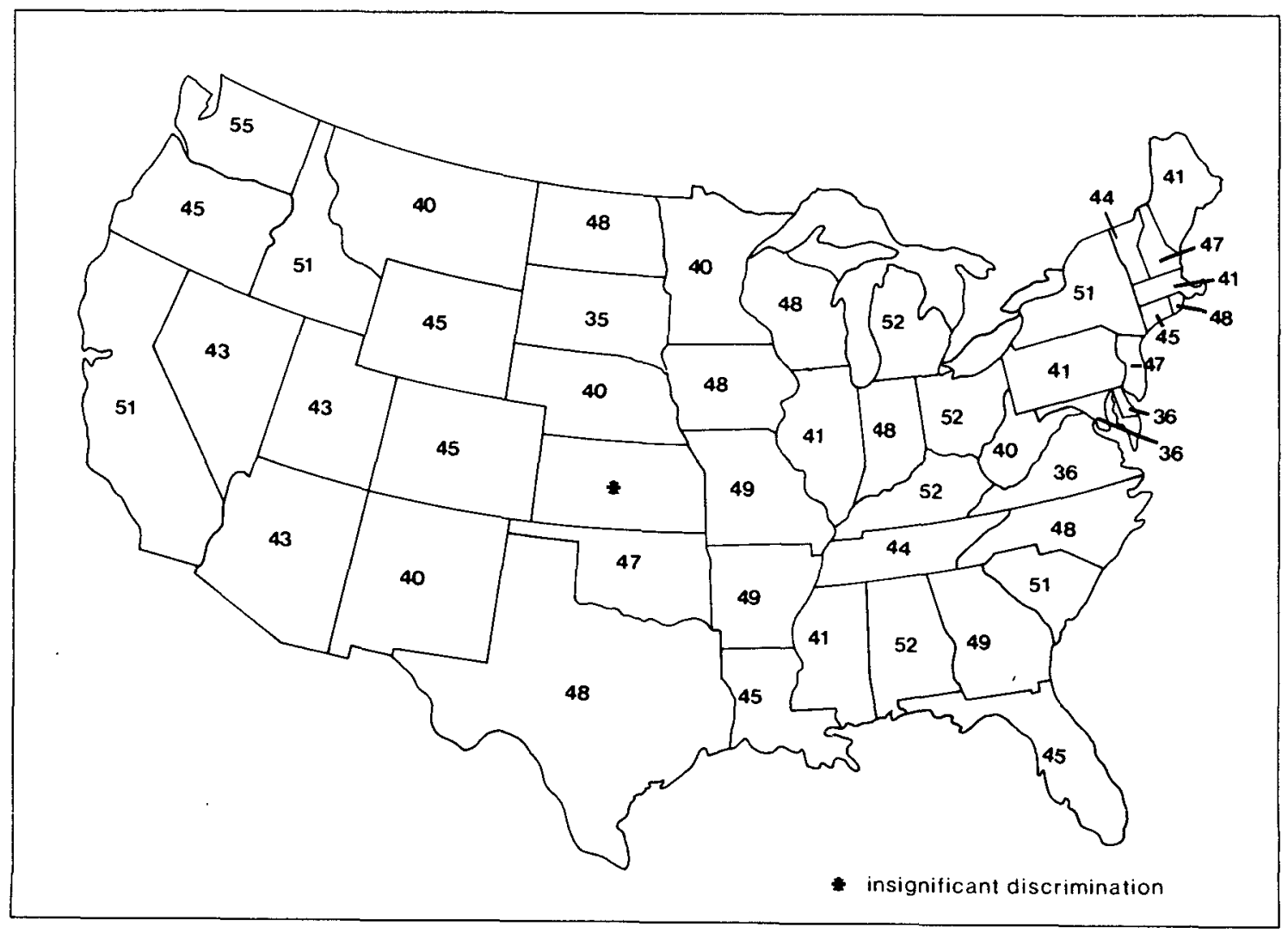

FiG. 4. Discriminant analysis: percentage of winters correctly classified, dependent period 1896-1970. 
(climate) patterns over time, but rather the temporal patterns that are defined by correlations among the 48 states for the time period ( $P$-mode analysis). Therefore, our eigenvectors constitute temporal variance structures that may be interpreted through space.

The characteristics of principal component analysis offer several advantages to initializing discriminant analysis. Since the eigenvectors are orthogonal, each individual component is completely independent of any other. As suggested before, interpretations based on multiple regression techniques are limited by possible high intercorrelations. Use of principal components that by definition are orthogonal eliminates this problem.

In addition, the components are arranged in order of variance accountability, such that the first eigenvector is the dominant mode of variability and each succeeding component accounts for the variance not explained by those preceeding it. The first few components normally account for a large portion of the total variance in the matrix. Rather than work with a large number of possible potential predictors, principal component analysis reduces the dataset to a more manageable size with little loss of explained variance.

Principal component analysis of the fall temperature of the continental United States yielded five factors that explain $89.3 \%$ of the total fall temperature variance. The communalities of the first five factors are high over most of the United States, particularly the Atlantic seaboard states (Fig. 2). Rather than work with derived data that would be difficult to obtain in operational forecasting, we linked each of the first five factors to the actual temperature data of the state that best represents it, i.e. the state that had the highest loading on that particular factor. Five representative states (Georgia, New Hampshire, Minnesota, New Mexico and Oregon, in order of their respective factors) together account for nearly eighty percent $(77.8 \%)$ of the total variance in autumn temperatures. The use of principal component analysis reduces the number of potential autumn predictors from 48 states to five representative states with a minimum loss of variance explained. These five predictor states, each having intercorrelations of less than 0.1 , provide the data for the derivation of discriminant functions.

Discriminant functions are in essence regression equations that have as their dependent variable groupmembership classes. These discriminant functions take the form:

$$
D_{i}=d_{i} Z_{1}+d_{i 2} Z_{2}+\cdots+d_{i p} Z_{p},
$$

where $D_{i}$ is the score on discriminant $i$, the $d$ s are weighting coefficients and the $Z s$ are the standardized

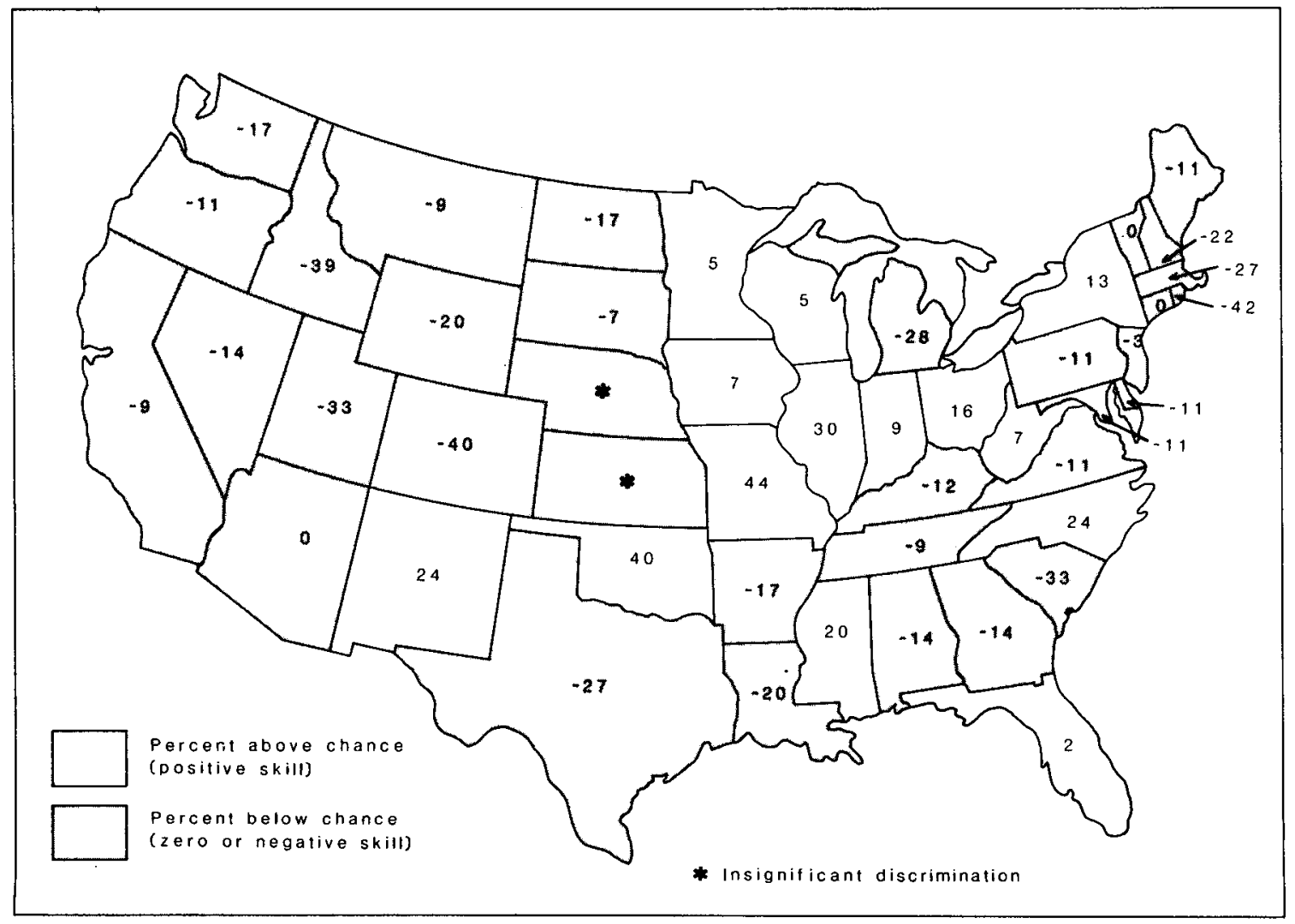

FIG. 5. Discriminant analysis summary skill: independent forecast period, autumn to winter 1970-78. 
values of the autumn temperature for the five representative states. Discriminant scores are first calculated for the seventy-five winters in the period 1896-1970 for every state. Ideally, the discriminant scores within a particular class (i.e., warm) should be closely grouped while the difference between classes (i.e., warm versus cold) would be maximized or distinct from the other classes. As the discriminant scores become more dispersed about the centroid of each class, the opportunity for class differentiation diminishes. In the case of Idaho, for example, the use of discriminant analysis resulted in the correct classification of $51 \%$ of the winter scores. Boundaries of these classes have been graphically represented by extending lines orthogonal to lines connecting their respective centroids (Fig. 3). As depicted in the graph, a two-class error occurred only eight times where the number of such errors expected by chance is sixteen. Note that the distance between the centroids of the warm and moderate classes is relatively small compared to the distance between the warm and cold classes. Thus, when seasonally forecasting for Idaho, one would expect better discrimination between warm and cold winters than between warm and moderate winters based on discriminant functions derived from antecedent fall temperatures. It also becomes evident, considering their respective centroid positions, that better classification in this example for Idaho can be achieved between moderate and cold winters than between moderate and warm seasons.

In a stochastic three-class system, one should expect to correctly classify a particular event $33.3 \%$ of the time. The correct classification of winter temperatures for individual states ranged from a low of $35 \%$ in South Dakota to a high of $55 \%$ in Washington, averaging $45.2 \%$ for the conterminous states (Fig. 4). This suggests a twelve percent improvement in classification of the base data (1895-1969) over that expected by chance. Regions of highest successful classification ( $>15 \%$ above chance) would generally include the far west and southeastern United States. Conversely, areas with discrimination barely exceeding chance include the central plains, and the midAtlantic states. Other research has similarly shown this marked drop in skill associated with the central states. Investigators using a variety of techniques and predictors (Namias, 1978b; Barnett, 1981b) found the central states to be an area of low predictability. This might be related to the low "potential predictability" (ratio of sampling variability to total record variability) of the region in winter (Madden and Shea, 1978; Barnett, 198 lb). Indeed, in this study, Kansas winters

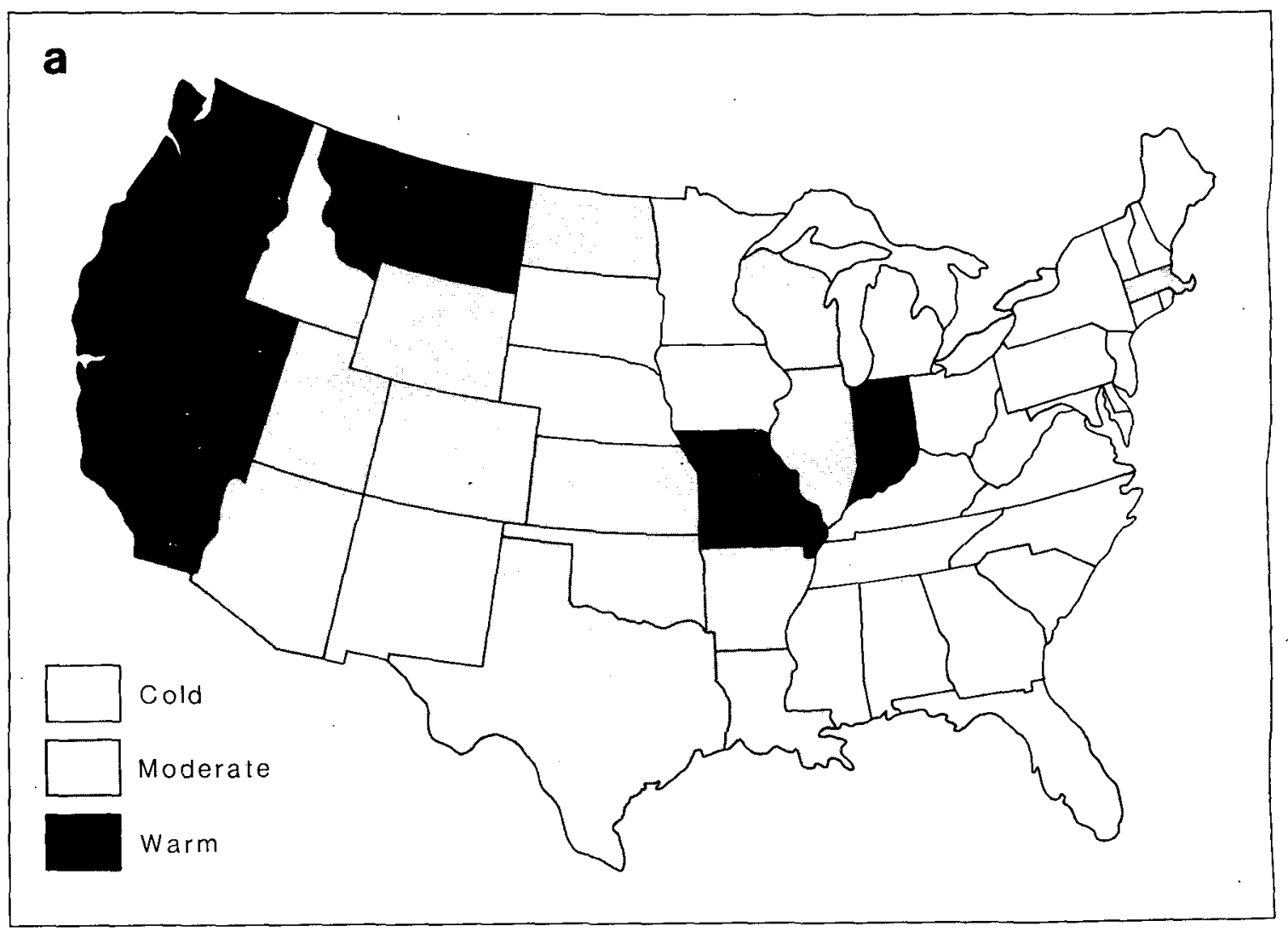

FIG. 6a. Contingency forecast: winter temperatures 1976/77. 
could not be forecast because of their lack of significance in the analytical techniques (based on a $F$-test of significance).

\section{d. Discriminant forecasts}

Discriminant functions were employed to forecast winter temperatures given antecedent autumn conditions during an independent period, 1970-78. Neither Kansas nor Nebraska winters could be predicted, again due to a lack of significant discrimination. Using the method described previously for contingency analysis, the accuracy of each discriminant forecast has been evaluated objectively by calculating the skill score. The summary skill score for the 46 states with forecast potential using discriminant functions for this time period was -0.04 . Only two states in the western half of the nation exhibited positive skill (Fig. 5). Recall that the aggregate skill derived using contingencies (Fig. 1) is identical $(-0.04)$ to that obtained with discriminant analysis. Although there appears to be a tendency for spatial contiguity in each map, the resultant spatial patterns are quite distinct. As stated earlier, contingency analysis for the independent forecast period seems to be most successful in the mountain states. Positive skill derived using discriminant analysis is predominant in the upper midwest. Only six states share common success using either forecasting technique.

Van Loon and Jenne (1975) cautioned that this trend in the data may complicate the successful derivation of seasonal forecasts when using regression equations, and the use of discriminant functions would be open to similar criticism. We attempted to correct for this possibility by repeating the discriminant analysis through substitution of a different eightyear independent period (1961-69). An aggregate skill of 0.03 reveals only slight improvement over the latter period, suggesting that the test period is not the determining factor in low skill scores.

\section{e. Comparative analysis}

Further insight into the attributes of these two techniques can be achieved by studying each individual winter forecast during the independent period. For example, Fig. 6a shows the winter forecast for 1976/77 (based upon observed conditions during autumn 1976) using the contingency tables previously derived for the 1895-1969 dependent period. Cold conditions were anticipated in the eastern United States; moderate temperatures were expected over the interior West and Rocky Mountains; and warmer than normal conditions were forecast for the far West.

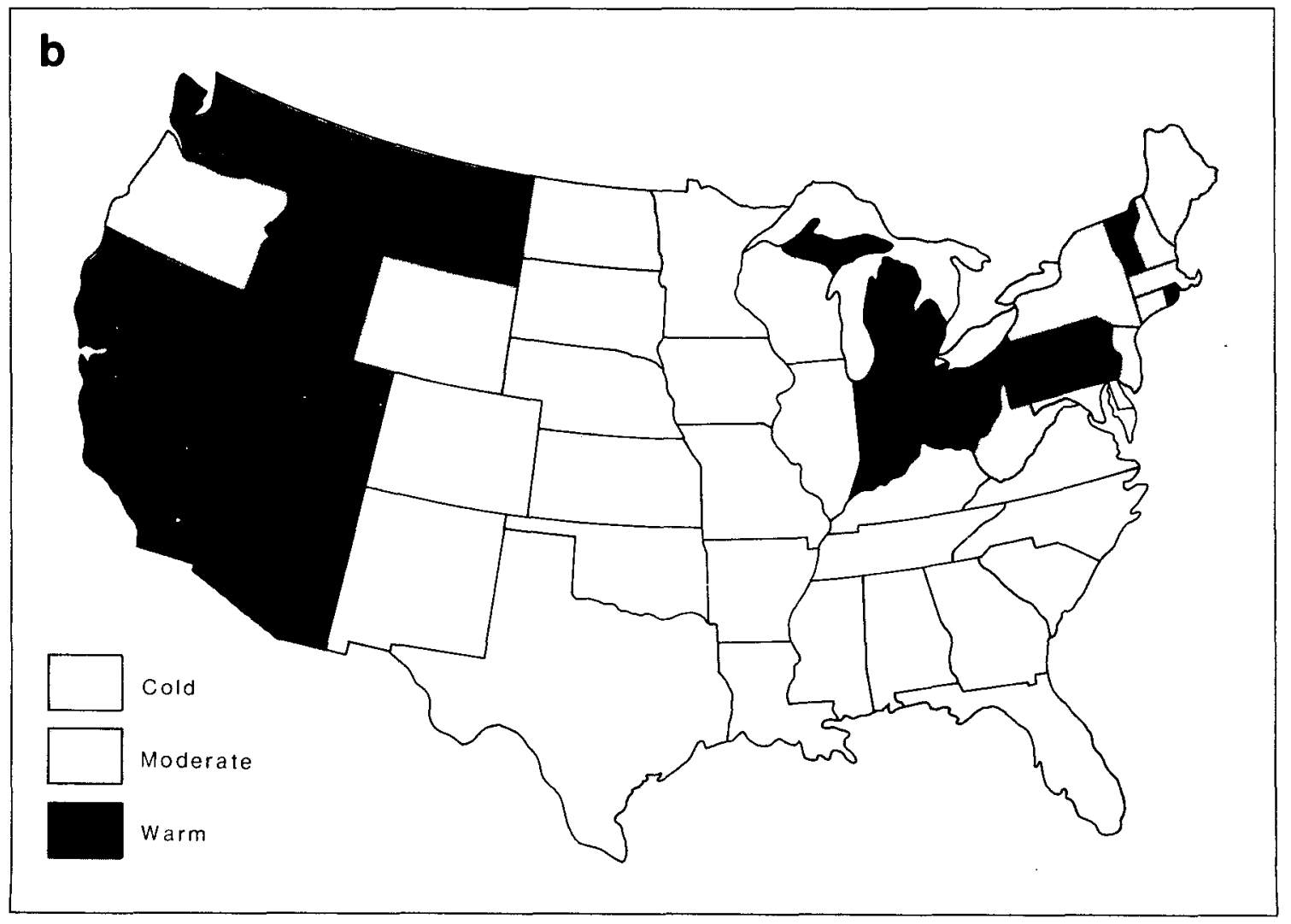

FIG. 6b. Discriminant forecast: winter temperatures 1976/77, 


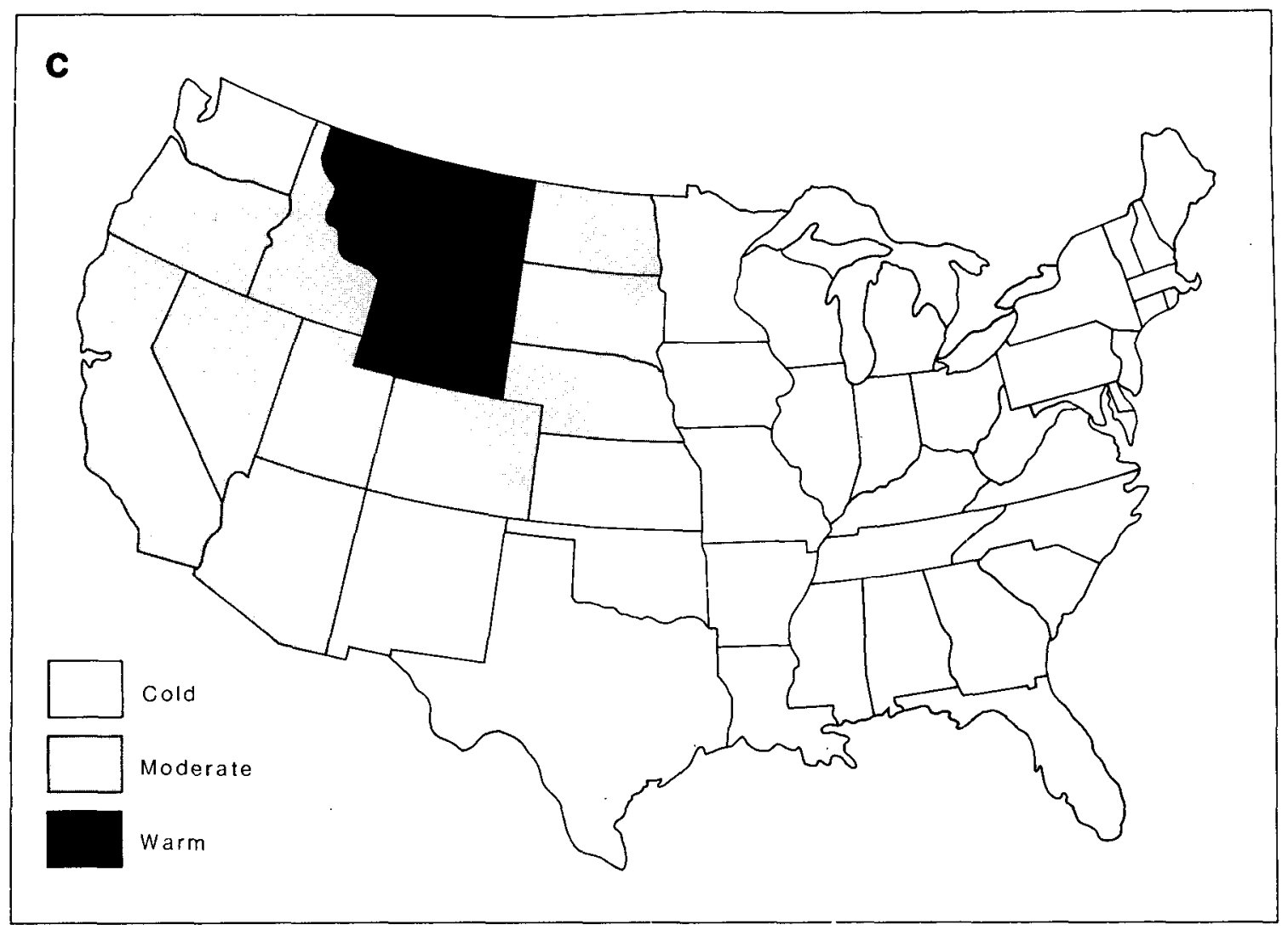

FIG. 6c. Observed winter temperatures 1976/77.

A similar forecast derived by using discriminant functions of the 1976 autumn temperatures in the United States (Fig. 6b) indicated cooler conditions would prevail over the entire south and upper midwest. The northeastern states were expected to be moderate to warm. The western third of the nation was predicted to be in the upper tercile range of temperatures. Both techniques anticipated cold conditions in the southeast and warm temperatures throughout the west. The most significant regional disparity would be in the northeast where the forecast techniques produced opposite expectations. The actual winter temperatures for $1976 / 77$ were observed to be well below normal in the eastern half of the nation, mostly in agreement with the contingency forecast (Fig. 6c). The warm temperatures expected in the far west by both forecasts were never realized. However, the warm conditions experienced in one of the two states (Montana) were anticipated by both techniques. The relative accuracy of each forecast is revealed in Table 1. As indicated, contingency factors permitted 39 state forecasts (no forecasts were made in nine states owing to a lack of any dominant antecedent relationship), of which 24 state forecasts were correct and only two forecasts were off by two classes. A positive skill score of 0.32 was associated with this seasonal forecast. Only 13 state forecasts were expected by chance to be correct, and nine state forecasts were expected to be incorrect by two classes.

Discriminant functions allowed more states to be forecast (46), but with less success. Although considerable success was achieved at forecasting cold con-

TABLE 1. Comparison of winter $1976 / 77$ forecasts by technique.

\begin{tabular}{|c|c|c|c|c|}
\hline \multirow[b]{2}{*}{ Observed } & \multicolumn{4}{|c|}{ Forecast } \\
\hline & Cold & Moderate & Warm & Total \\
\hline \multicolumn{5}{|c|}{ Contingency forecast: Winter $1976 / 77$} \\
\hline $\begin{array}{l}\text { Cold } \\
\text { Moderate } \\
\text { Warm }\end{array}$ & $\begin{array}{r}18 \\
2 \\
0\end{array}$ & $\begin{array}{l}6 \\
5 \\
1\end{array}$ & $\begin{array}{l}2 \\
4 \\
1\end{array}$ & $\begin{array}{r}26 \\
11 \\
2\end{array}$ \\
\hline $\begin{array}{l}\text { Total } \\
\text { Skill score }=0.32\end{array}$ & 20 & 12 & 7 & 39 \\
\hline \multicolumn{5}{|c|}{ Discriminant forecast: Winter $1976 / 77$} \\
\hline $\begin{array}{l}\text { Cold } \\
\text { Moderate } \\
\text { Warm }\end{array}$ & $\begin{array}{r}21 \\
2 \\
0\end{array}$ & $\begin{array}{l}7 \\
2 \\
1\end{array}$ & $\begin{array}{l}6 \\
6 \\
1\end{array}$ & $\begin{array}{r}44 \\
10 \\
2\end{array}$ \\
\hline $\begin{array}{l}\text { Total } \\
\text { Skill score }=0.16\end{array}$ & 23 & 10 & 13 & 56 \\
\hline
\end{tabular}


ditions by both techniques, the discriminant functions tended to overforecast warm conditions. This led to six state forecasts that were off by two classes, 16 off by one class, and a resultant skill score of only 0.16 .

The aggregate of forecasts made for the entire independent period is summarized in Table 2. Dominant contingency associations permitted a total of 321 usable state forecasts. Of these, 105 forecasts were correctly classified (where 107 would be expected by chance); 149 were off by one class (143) and 67 missed by two classes (71). As reported before, the total skill associated with this performance is -0.04 .

Discriminant analysis resulted in more state forecasts (368) for the same period, but achieved an identical skill score of -0.04 . Whereas the number of two class errors was small (only 64 when 82 would be expected), this success was nullified by an inordinate number of one class errors (190 as compared to an expected 164). One would conclude from these results that antecedent fall conditions explain little of the winter variance pattern during the independent test period.

\section{f. Canonical analysis}

As noted above, one of the problems associated with contingency analysis is the imposed spatial limitation of restricting antecedent conditions to the areal extent of a particular state. This limitation is somewhat relaxed in our derivation of discriminant functions based on factor analyzed spatial patterns of fall temperatures, represented in turn by five (5) representative states. Canonical correlation analysis appears to be a viable technique for relating the total variance of fall temperatures to that of the winter temperatures for the entire United States. The goal of canonical correlation analysis is to devise a linear combination from each of two spatial patterns of

TABLE 2. Aggregate of winter $1970-78$ forecasts by technique.

\begin{tabular}{|c|c|c|c|c|}
\hline \multirow[b]{2}{*}{ Observed } & \multicolumn{4}{|c|}{ Forecast } \\
\hline & Cold & Moderate & Warm & Total \\
\hline \multicolumn{5}{|c|}{ Contingency forecast } \\
\hline $\begin{array}{l}\text { Cold } \\
\text { Moderate } \\
\text { Warm }\end{array}$ & $\begin{array}{l}48 \\
33 \\
39\end{array}$ & $\begin{array}{l}30 \\
34 \\
38\end{array}$ & $\begin{array}{l}28 \\
48 \\
23\end{array}$ & $\begin{array}{l}106 \\
115 \\
100\end{array}$ \\
\hline Total & 120 & 102 & 99 & 321 \\
\hline \multicolumn{5}{|c|}{ Discriminant forecasts } \\
\hline $\begin{array}{l}\text { Cold } \\
\text { Moderate } \\
\text { Warm }\end{array}$ & $\begin{array}{l}39 \\
39 \\
33\end{array}$ & $\begin{array}{l}54 \\
34 \\
41\end{array}$ & $\begin{array}{l}31 \\
56 \\
41\end{array}$ & $\begin{array}{l}124 \\
129 \\
115\end{array}$ \\
\hline $\begin{array}{l}\text { Total } \\
\text { Skill score }\end{array}$ & 111 & 129 & 128 & 368 \\
\hline
\end{tabular}

temperature (fall and winter) in such a way that the correlation between the two linear combinations is maximized. Thus canonical correlation can be used to isolate seasonal patterns in winter temperature data over the United States that are correlated in time with fall temperature patterns for the same region (Glahn, 1968; Brinkmann, 1980; Lawson and Stockton, 1981).

The extraction of pairs of linear combinations (canonical variates) is similar to the derivation of principal components, except that it is not the goal of canonical correlation to account for as much shared variance as possible within one set of variables. Instead, canonical analysis maximizes the variance between the sets of variables. We initialize the canonical correlation procedure by deriving two sets of variables to produce a matrix of 48 state-weighted autumn temperatures over 83 years (1895-1978) and a similar matrix of winter temperatures.

The variance between any pair of canonical variates $R^{2}$ is first multiplied by the squared loading for the sth state on the $i$ th pair of canonical variates $\left(r_{i s}{ }^{2}\right)$. The summation of this product over all pairs,

$$
\sum_{i=1}^{n} R_{i}^{2} r_{i s}^{2}
$$

is the total variance in a particular state explained by the variance in the other matrix (in this case, the fall temperatures). For example, the first canonical variate pair explains $0.4 \%$ of the total variance in the winter temperature of Alabama, the second pair explains $6 \%$, and the third accounts for another $6 \%$. The first twenty pairs explain $38 \%$ of the total variance in the winter temperatures of Alabama. Similarly, low values were produced throughout the remaining states, particularly in the northwest which typically had only $25 \%$ of the variance in winter temperatures explained by the fall temperatures through the first twenty canonical pairs. The most success achieved through variance explained is in Missouri with $64 \%$, but no region of potential predictability seems to dominate the spatial pattern. The first 20 canonical variate pairs pass the Bartlett's chi-square test for significance. If we restrict our consideration to these pairs, we find that using twenty pairs, $41 \%$ of the variance in winter temperature across the United States is associated with $34 \%$ of the antecedent fall pattern of temperatures. This indicates that each pair explains only a few percent of the variance of each dataset, and therefore suggests that fall and winter temperature patterns are unrelated.

\section{Summary}

Three different methodologies have been used to investigate the potential of seasonal forecasting. In 
particular, examination of the predictability of winter temperatures by autumn temperatures was made by contingency analysis, discriminant analysis, and canonical correlation analysis.

Contingency tables were constructed based on tercile classifications of a seventy-five year period of seasonal temperatures. Testing of an independent data period using these tables produced skill scores that were not significant. Discriminant analysis used linear combinations of the antecedent seasonal temperatures to distinguish between specific terciles of the predictant season. As with contingency analysis, initial examination of the base seventy-five years of data was promising. Over half of the states (28) had $45 \%$ or more of their winter temperatures in this base period correctly grouped through the use of representative autumn temperatures; yet, as with contingency analysis, the independent test period was unable to be forecast with any appreciable skill for the United States as a whole.

Canonical correlation analysis provides an overall study of the relationship between autumn and winter state-averaged temperatures. This analysis creates linear combinations of fall and winter temperatures that have correlations which are maximized. Summation of the first 20 canonical variate pairs suggest that autumn and winter temperatures over the continental United States are not closely related to one another, given the low amount of shared variance.

These three methodologies address the potential for antecedent seasonal temperature patterns for use in the forecasting of successive seasonal temperatures. No significant skill is found in forecasting of the winter temperatures of an independent data period using either contingency or discriminant analysis. Canonical analysis suggests that little correlation exists between autumn and winter temperatures over an eighty-three year period of record. It must be recognized that other research suggests there may be as much or even greater skill from persistence-contingency analyses using summer as a predictor for fall (e.g., Namias, 1978b), or using a shorter antecedent period, such as the use of November temperatures to forecast winter (Lawson et al., 1978). Perhaps this possibility could best be addressed by systematically employing these techniques (contingency, discriminant, and canonical analyses) for various antecedent time periods. Given our findings, however, one has little about which to be optimistic in persistencereversal temperature forecasting using antecedent seasonal temperature. Climatological forecasting of this type does not appear to improve the skill in seasonal forecasting.

Acknowledgments. The authors wish to thank Robert Balling for his helpful comments concerning our research design and initial manuscript. We also express our appreciation to the anonymous reviewers for their excellent suggestions and comments. We are indebted to Les Howard of the Cartographic Laboratory, UN-L, for preparing our graphics. Our sincere thanks are also expressed to Ms. Gail Osborne for patiently typing the manuscript.

\section{REFERENCES}

American Meteorological Society, 1983: Policy statement of the American Meteorological Society on weather forecasting. Bull. Amer. Meteor. Soc., 64, 1385-1387.

Balling, R. C., 1984: Classification in climatology. Spatial Statistics and Models, G. L. Gaile and C. J. Willmott, Eds, Reidel, 81108.

Barnett, T. P., 1981a: Statistical relations between ocean/atmosphere fluctuations in the tropical Pacific. J. Phys. Oceanogr., 11, 1043-1058.

— 1981 b: Statistical prediction of North American air temperatures from Pacific predictors. Mon. Wea. Rev., 109, 10211041.

, and K. Hasselman, 1979: Techniques of linear prediction with application to oceanic and atmospheric fields in the tropical Pacific. Rev. Geophys. Space Phys., 17, 949-968.

Bettge, T. W., D. Baumhefner and R. Chervin, 1981: On the verification of seasonal climate forecasts. Bull. Amer. Meteor. Soc., 62, 1654-1665.

Brinkmann, W. A. R., 1980: Lake Superior area temperature variations. Ann. Assoc. Amer. Geogr. 70, 17-30.

Changnon, S. A., Jr., 1979: How a severe winter impacts on individuals. Bull. Amer. Meteor. Soc., 60, 110-114.

Chervin, R. M., J. E. Kutzbach, D. D. Houghton and R. G. Gallimore, 1980: Response of the NCAR General Circulation Model to prescribed changes in ocean surface temperature. Part II: Midlatitude and subtropical changes. J. Atmos. Sci., 37, 308-332.

Diaz, H. F., and R. G. Quayle, 1978: The 1976-77 winter in the contiguous United States in comparison with past records. Mon. Wea. Rev., 106, 1393-1421.

—, and D. C. Fulbright, 1981: Eigenvector analysis of seasonal temperature, precipitation and synoptic-scale system frequency over the contiguous United States. Part I: Winter. Mon. Wea. Rev., 109, 1267-1284.

Gilman, D. L., 1957: Empirical orthogonal functions applied to thirty-day forecasting. Sci. Rep. 1, Contract AF 19(604)-1283, MIT, Cambridge, MA, $129 \mathrm{pp.}$

Glahn, H. R., 1968: Canonical correlation and its relationship to discriminant analysis and multiple regression. J. Atmos. Sci., 25, 23-31.

Lawson, M. P., and C. W. Stockton, 1981: Desert myth and climatic reality. Ann. Assoc. Amer. Geogr., 71, 527-535.

—, A. Douglas and P. Englehart, 1978: Analysis of seasonal persistence of climate in Nebraska. Occasional Papers No. 4. Department of Geography, University of Nebraska, 143 pp.

- , K. F. Dewey and R. Heim, Jr., 1984: Climatological contingency analysis and seasonal forecast skill in the United States. J. Climatol. 4, 205-215.

Madden, R. A., and D. J. Shea, 1978: Estimates of the natural variability of time-averaged temperature over the United States. Mon. Wea. Rev., 106, 1695-1703.

McCullough, C. A., 1983: Short-term climate predictions for water management. Bull. Amer. Meteor. Soc., 64, 1273-1275.

Namias; J., 1964: A five-year experiment in the preparation of seasonal outlooks. Mon. Wea. Rev., 92, 449-464. 
—_ 1968: Long-range weather forecasting-history, current status and outlook. Bull. Amer. Meteor. Soc., 49, 438-470.

_- 1978a: Long-range weather and climate predictions. Geophysical Predictions, Natl. Acad. Sci., Washington, DC, 103114.

- 1978b: Persistence of U.S. seasonal temperatures up to one year. Mon. Wea. Rev., 106, 1557-1567.

Nicholls, N., 1980: Long-range weather forecasting: Value, status, and prospects. Rev. Geophys. Space Phys., 18, 771-788.

Phillips, L. D., C. R. Peterson and T. W. Keelin, 1978: The value of improved forecasts of climate for agricultural decision making. Final Rep. PR-77.7-44, Decisions and Designs, McLean, VA.

Pielke, R. W., 1977: An overview of recent work in weather forecasting and suggestions for further work. Bull. Amer. Meteor. Soc., 58, 404-407.
Preisendorfer, R. W., and C. D. Mobley, 1984: Climate forecast verifications, United States mainland, 1974-83. Mon. Wea. Rev., 112, 809-825.

Quayle, R. G., and H. F. Diaz, 1980: Heating degree day data applied to residential heating energy consumption. J. Appl. Meteor., 19, 241-246.

Riebsame, W. E., 1983: News media coverage of seasonal forecasts: The case of winter 1982-83. Bull. Amer. Meteor. Soc., 64, $1351-1356$.

Shelton, M. L., 1978: Drought to flood-a sudden moisture reversal in California. Weatherwise, 31, 92-100.

van Loon, H., and R. L. Jenne, 1975: Estimates of seasonal mean temperature using persistence between seasons. Mon. Wea. Rev., 103, 1121-1128.

Warren, H. E., and S. K. LeDuc, 1981: Impact of climate on energy sector in economic analysis. J. Appl. Meteor., 20, 14311439. 